\title{
Different outcomes of infection of chickens and ducks with a duck-origin H9N2 influenza A virus
}

\author{
J. WANG ${ }^{*}$, C. C. LI", Y. X. DIAO*, X. Y. SUN, D. M. HAO, X. LIU, P. P. GE \\ Zoology Institute, Agricultural University of Shan Dong Province, Dai Zong Avenue 61, Taian City 271018, \\ Shan Dong Province, P. R. China
}

Received October 23, 2013; accepted July 30, 2014

\begin{abstract}
Summary. - As the major aquatic and terrestrial hosts for avian influenza viruses (AIVs), ducks and chickens play a critical role in the evolution and spread of the H9N2 virus. However, the outcomes of infection of ducks and chickens with the H9N2 virus are not sufficiently documented. In this study, we compared the outcomes of infection of chickens and Peking ducks with a duck-origin H9N2 virus. The results showed that this virus caused more pronounced clinical signs and histological lesions in chickens. As for the virus shedding, chickens shed more virus in the trachea and less virus in the cloaca in levels of interferon (IFN) $\gamma$ were found in the trachea of ducks compared with chickens, while comparison with ducks. As for cytokines, namely IFNs and interleukins (IL), higher higher levels of IFN- $\beta$, IFN- $\gamma$, IL-1 $\beta$, and IL- 6 were observed in the ileum of chickens compared with ducks. Eventually, serum hemagglutination-inhibition (HI) antibody titers were higher in chickens than in ducks. Taken together, ducks and chickens use different strategies in response to the H9N2 virus infection in tissues representing main replication sites of low-pathogenic AIVs. Given the different outcomes of the H9N2 virus infection in ducks and chickens, different measures should be taken in vaccination and treatment.
\end{abstract}

Keywords: duck-origin influenza A virus; H9N2 subtype; chicken; duck

\section{Introduction}

Avian influenza viruses (AIVs) have been well documented to reside in the aquatic birds of the world (Olsen $e t$ al., 2006). They are classified into subtypes based on surface glycoproteins, hemagglutinin (HA) and neuraminidase (NA). Of special interest to medicine and agriculture, ducks are considered the principal natural reservoir for AIV and harbor any combination of the $16 \mathrm{HA}$ and 9 NA subtypes that are currently identified, with the exception of the H13

Corresponding author. E-mail: yxdiao@126.com; phone: +86 0538 8249851-8210. "These authors contributed equally to this work.

Abbreviations: $\operatorname{AIV}(\mathrm{s})=$ avian influenza virus(es); $\mathrm{CL}=$ cloacal; $\mathrm{HA}=$ hemagglutinin; $\mathrm{HI}=$ hemagglutination-inhibition; HPAIVs = highly pathogenic avian influenza viruses; IFN = interferon; $\mathrm{IL}=$ interleukin; $\operatorname{LPAIV}(\mathrm{s})=$ low pathogenic avian influenza virus(es); $\mathrm{NA}=$ neuraminidase; $\mathrm{OP}=$ oropharyngeal; p.i. = post infection and H16 subtypes (Webster et al., 1992; Munster et al., 2007). Most AIV isolates have been reported from dabbling ducks in the subfamily Anatinae. These duck-origin viruses were typically identified as low pathogenic AIVs (LPAIVs) based on their virulence in domestic galliformes and the amino acid sequence at the HA cleavage site (Lee et al., 2007). Although all subtypes of AIV circulate and evolve in the wild aquatic birds, only viruses of subtypes $\mathrm{H} 5$ and H7 have historically mutated to highly pathogenic avian influenza viruses (HPAIVs) after circulating in domestic poultry (Alexander, 2000).

While HPAIVs have become widespread across continents, causing huge economic losses to poultry farming, one subtype belonging to LPAIVs, H9N2, has also attracted a particular attention. Since the first isolation from terrestrial birds (quails) in 1988, H9N2 became prevalent in China and, occasionally, infected a wide range of species, including humans, dogs, cats, pigs, and a wide variety of domesticated birds (Peiris et al., 1999; Xu et al., 2004; Bi et al., 2010; Zhang 
et al., 2013). It has been reported that $\mathrm{H} 9 \mathrm{~N} 2$ might provide internal genes to the lethal 1997 Hong Kong H5N1 viruses that caused six fatal cases out of 18 infected patients (Guan et al., 1999). Genetic analysis has shown that the recently emerged human H7N9 virus derived six gene segments from H9N2 (Gao et al., 2013). Moreover, some currently circulating H9N2 viruses have acquired the capacity to bind [alpha] 2-6 sialic acids found in the mammalian upper respiratory tract (Matrosovich et al., 2001). Given the wide distribution of $\mathrm{H} 9 \mathrm{~N} 2$ viruses and the capacity to infect humans and pigs, H9N2 viruses have the potential ability to cause a future human influenza pandemic.

As the major aquatic and terrestrial hosts for AIV, ducks and chickens play a critical role in the transmission and evolution of H9N2. Multiple experimental trials with H9N2 have been conducted in chickens and the infection caused syndromes including decrease in egg production, delays in growth, mild respiratory distress, and even death in the immunosuppressed models or models co-infected with a secondary pathogen (Bano et al., 2003; Kishida et al., 2004; Kwon et al., 2008). Although experimental LPAIV infections in ducks have been reported with the outcomes varying from asymptomatic infection to the induction of respiratory disease evident as sinusitis, conjunctivitis, and lower respiratory tract lesions (Jackwood et al., 2010; Spackman et al., 2010; Maughan et al., 2013), the current knowledge of H9N2 infection of ducks is still very limited. Furthermore, there are few studies concerning the comparison of outcomes of H9N2 infection between ducks and chickens. Therefore, in this study, we compared the outcomes of infection of chickens and Peking ducks with duck-adapted H9N2 influenza A virus. In particular, clinical signs, virus shedding, microscopic lesions and immune responses to the virus were followed.

\section{Materials and Methods}

Virus and birds. The H9N2 virus (A/duck/SD/006/2010), hereafter named H9N2, was isolated from a Peking duck (Anas platyrhynchos domesticus). After the third passage in 9-day-old SPF embryonated chicken eggs, the virus was titrated to determine EID $_{50} .1$-day-old SPF white leghorn chickens were obtained from a local commercial supplier of SPF animals. Because of no SPF ducks available, 1-day-old Peking ducks were purchased from a local hatchery. Birds were housed in SPF isolators until they were exposed at 2 weeks of age.

Experimental design. The experiment was approved by the Committee on the Ethics of Animal of Shandong. Prior to exposure, all birds were seronegative to H9N2 tested by HI test. Experimental groups were housed separately, one group per isolator. The experimental procedures conducted in ducks were identical to procedures used in chickens, unless stated otherwise.

Forty ducks (chickens) were evenly divided into two groups: control group and H9N2-inoculated group. At 2 weeks of age, each duck (chicken) was intranasally inoculated with $100 \mu$ of inoculum containing $10^{7} \mathrm{EID}_{50}$ of the virus. Birds in the two control groups received $100 \mu$ of sterile PBS in the same manner. After inoculation, all birds were monitored daily for clinical signs of the disease for 14 days, and were scored as follows: $0=$ no clinical signs, $1=$ mild depression, decreased activity and mild respiratory signs, 2 = depression, diarrhea, anorexia and moderate respiratory signs, $3=$ severe depression and respiratory signs, $4=$ dead.

Oropharyngeal (OP) and cloacal (CL) swabs were collected at 2, $4,7,10$, and 14 days post infection (p.i.) from five birds to evaluate virus shedding. In addition, on day 1, 4 and 7 p.i., five birds from each group were euthanized and necropsied. Tissues from five birds were collected for histopathology and a portion of the collected trachea and ileum were snap-frozen in liquid nitrogen and stored at $-70^{\circ} \mathrm{C}$ for RNA isolation and further analysis of immune-related gene

Table 1. PCR primers

\begin{tabular}{lllll}
\hline \multirow{2}{*}{ Gene } & Host & Forward primer $\left(5^{\prime}-3^{\prime}\right)$ & Reverse primer $\left(5^{\prime}-3^{\prime}\right)$ & GenBank Acc. No. \\
\hline \multirow{2}{*}{ GAPDH } & Chicken & CCTCTCTGGCAAAGTCCAAG & CATCTGCCCATTTGATGTTG & V00407 \\
\cline { 2 - 5 } & Duck & ATGTTCGTGATGGGTGTGAA & CTGTCTTCGTGTGTGGCTGT & AY436595 \\
\hline \multirow{2}{*}{ IFNA } & Chicken & ATGCCACCTTCTCTCACGAC & AGGCGCTGTAATCGTTGTCT & EU367971 \\
\cline { 2 - 6 } & Duck & TCCTCCAACACCTCTTCGAC & GGGCTGTAGGTGTGGTTCTG & EF053034 \\
\hline \multirow{2}{*}{ IFNB } & Chicken & CCTCAACCAGATCCAGCATT & GGATGAGGCTGTGAGAGGAG & \multirow{2}{*}{ AY831397 } \\
\cline { 2 - 5 } & Duck & & & DQ906156 \\
\hline \multirow{2}{*}{ IFNG } & Chicken & GCTGACGGTGGACCTATTATT & TGGATTCTCAAGTCGCTCATCG & AJ012254 \\
\cline { 2 - 5 } & Duck & Duck GCTGATGGCAATCCTGTTTT & GGATTTTCAAGCCAGTCAGC & NM204524 \\
\hline \multirow{2}{*}{ IL1B } & Chicken & GCTCTACATGTCGTGTGTGATGAG & TGTCGATGTCCCGCATGA & DQ393268 \\
\hline \multirow{2}{*}{ IL2 } & Duck & TCGACATCAACCAGAAGTGC & GAGCTTGTAGCCCTTGATGC & AY510091 \\
\hline \multirow{2}{*}{ IL6 } & Chicken & CGGGATCCATGATGTGCAAAGTACTG & CGGTCGACTTATTTTTGCAGATATCT & EU170468 \\
\cline { 2 - 5 } & Duck & GCCAAGAGCTGACCAACTTC & ATCGCCCACACTAAGAGCAT & AB302327 \\
\cline { 2 - 5 }
\end{tabular}


expression levels. For the determination of $\mathrm{HI}$ antibodies titers, the remaining five ducks (chickens) were kept for one more week. Serum samples were collected on day $0,3,7,10,14,17$, and 21 p.i.

Virus isolation and titration. The collected OP and CL swabs were collected in PBS containing antibiotics and stored at $-70^{\circ} \mathrm{C}$. Titers of infectious virus (expressed as $\mathrm{EID}_{50}$ ) were determined by Reed and Muench method (Reed and Muench, 1938).

Histopathology. Samples of heart, trachea, lung, spleen, pancreas, liver, kidney, ileum, bursa of Fabricius (BF) were fixed in $10 \%$ neutral buffered formalin for histopathology. After $48 \mathrm{hr}$ fixation, samples were routinely processed and embedded into paraffin blocks. $4 \mu \mathrm{m}$ sections were counterstained with hematoxylin and eosin (H\&E) and examined under light microscopy. The severity of lesions was scored as follows: (-) none; (+/-) minimal; (+) mild; $(++)$ moderate; $(+++)$ high.

RNA extraction. Total RNA was extracted from tissue homogenates in Trizol (Invitrogen) following the manufacturer's instructions. RNA was DNAse-treated and cDNA was synthesized using PrimeScript $^{\text {tax }}$ II 1st Strand cDNA Synthesis Kit (TaKaRa, DaLian, China) following the manufacturer's instructions.

Assay of cytokines by real-time RT-PCR. The relative quantitation of immune-related gene expression levels in the samples after infection was determined using the Applied Biosystems 7500 Fast Real-Time PCR System (Applied Biosystems, CA). Primers used in this study were previously reported (Adams et al., 2009). The selected primers are shown in Table 1. PCR conditions were the same for each targeted gene and were as follows: $95^{\circ} \mathrm{C}$ for $30 \mathrm{sec}$, followed by 45 cycles of $95^{\circ} \mathrm{C}$ for 15 sec, $58^{\circ} \mathrm{C}$ for $32 \mathrm{sec}$ and $72^{\circ} \mathrm{C}$ for $20 \mathrm{sec}$. Cycling was terminated after 45 cycles with dissociation curves. The $2^{-\Delta \Delta \mathrm{CT}}$ method was used for quantification of target gene expression using GAPDH gene as the reference gene for data normalization (Livak and Schmittgen, 2001). Additionally, due to an error in processing samples collected at 7 days p.i., only samples collected on day 1 and 4 p.i. were analyzed.

Titration of HI antibodies. Serum samples were obtained from the whole blood and tested for the antigen-specific antibody titers against H9N2 following the WHO standard.

Statistical analysis. Data were expressed as means \pm standard error (SE). Statistical differences between the means for two groups were evaluated using two-tailed Student's unpaired $t$-test with the level of significance at $P \leq 0.05$.

\section{Results}

\section{Clinical signs and virus shedding}

As shown in Fig. 1a, the primary clinical signs presented by ducks were mild nasal discharge and tearing 3-5 days p.i. with clinical score ranging from $0-0.2$. On the other indicated days p.i., infected ducks were asymptomatic. As for
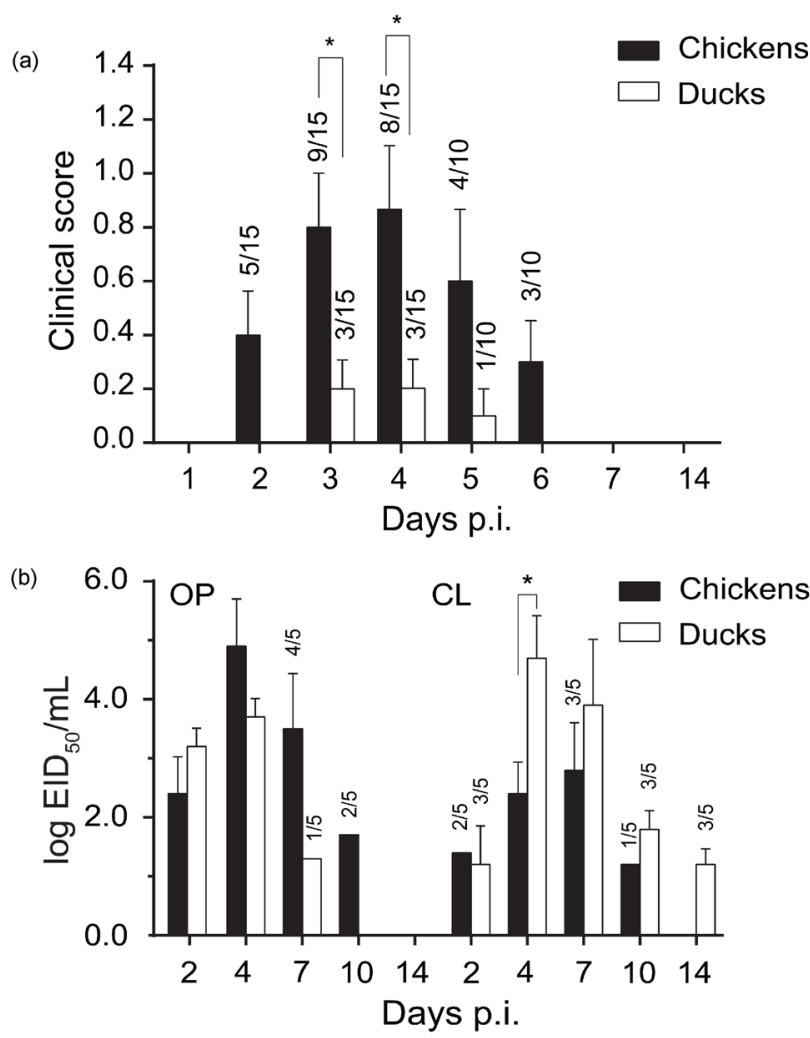

Fig. 1

Clinical signs and virus shedding in chickens and ducks infected with H9N2

The ratios above columns indicate the number of birds showing clinical signs/ examined birds (a) and the number of postive/examined swab samples (b). Data are means \pm standard error (SE). Asterisk indicates a significant difference.

the infected chickens, clinical signs were primarily depression, sneezing and decreased feed and water intake, which occurred 2-6 days p.i. and disappeared 7-14 days p.i.. No mortality occurred in chickens and ducks after infection. However, it appeared that more chickens than ducks manifested clinical signs after infection.

Based on the results of virus shedding presented in OP and CL swabs (Fig. 1b), the pattern of viral shedding, including the amount of the virus and viral persistence, varied between ducks and chickens. In chickens, virus shedding collected from OP presented higher titer levels than CL swabs. Meanwhile in ducks, there appeared greater positive recovery rates and longer persistence of viral shedding in CL swabs. Moreover, 4 days p.i., CL swabs from ducks displayed significantly higher titers than those from chickens. Taken together, chickens shed more virus in the trachea and less virus in the cloaca in comparison with ducks. 

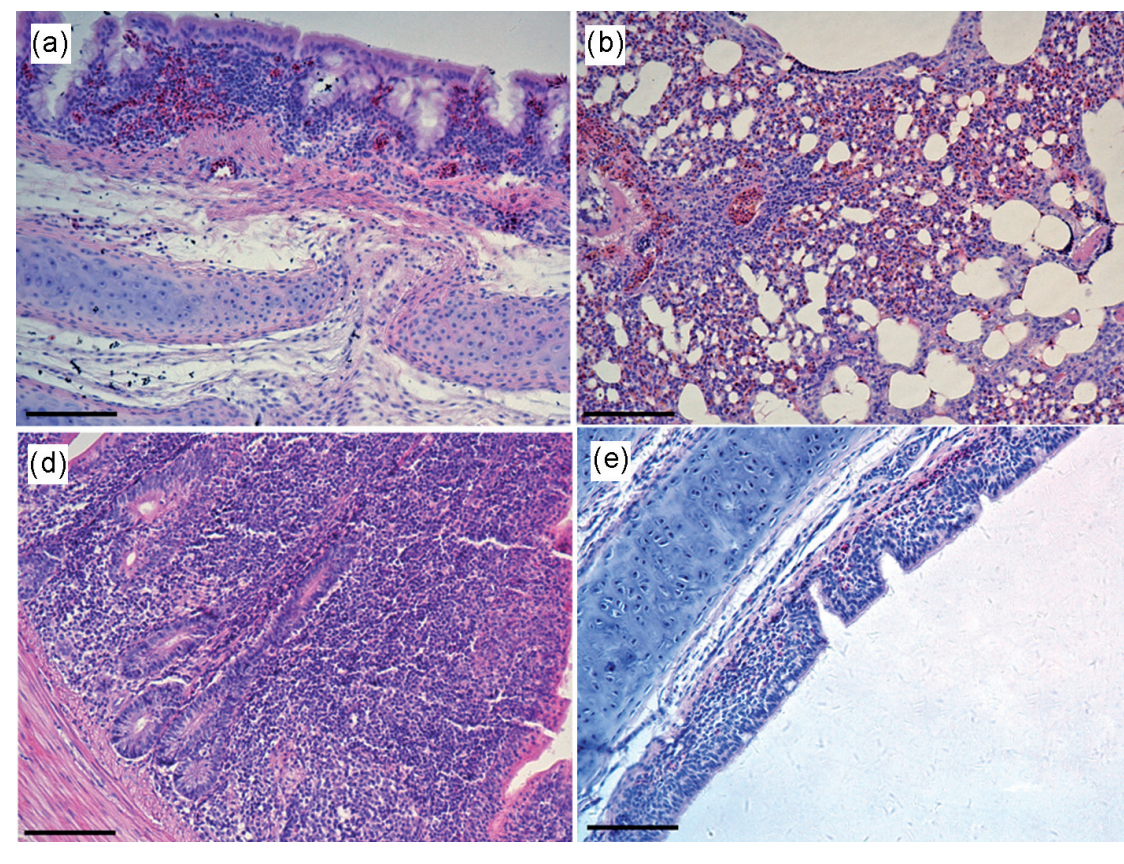

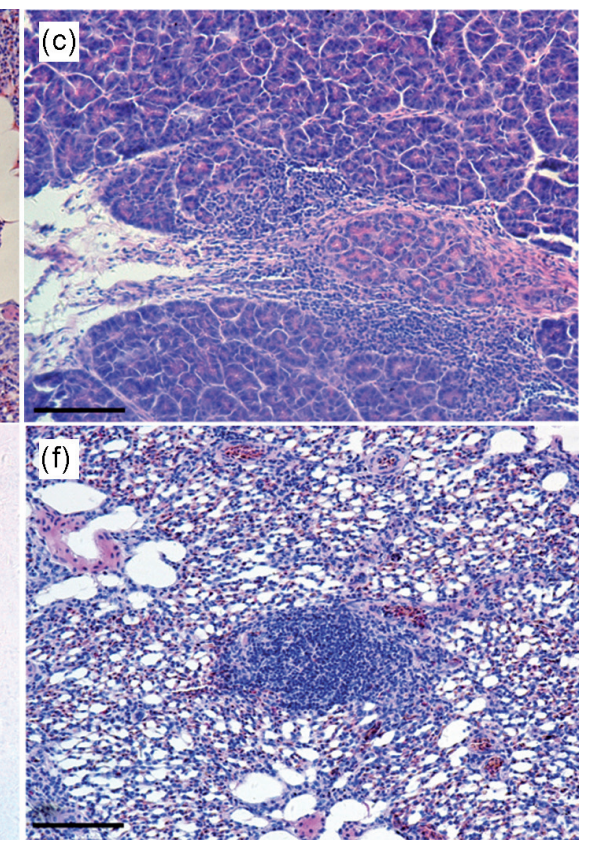

Fig. 2

Histopathological lesions in tissues of chickens and ducks infected with H9N2

Day 4 p.i. Chicken trachea (a), lungs (b), pancreas (c) and ileum (d). Duck trachea (e) and lungs (f). Bar $=100 \mu \mathrm{m}$.

\section{Histopathology}

The microscopic lesions after infection were mainly confined to the respiratory tracts in chickens (Table 2). On 4 days p.i., lesions in the respiratory tracts were more predominant in virus-infected chickens and ducks. Three of five chickens displayed lesions in the tracheas consisting of mild to moderate lymphocytic infiltration mixed with red blood cells and mild edema in the submucosa (Fig. 2a). In the lungs, mild to moderate congestion and inflammatory cells around bronchi and blood vessels were present in four of five chickens (Fig. 2b). Lesions in pancreata were mainly mild to moderate inflammatory cells infiltration (Fig. 2c). Also, mild to moderate enteritis developed in chickens after infection (Fig. 2d). As for other tissues examined, minimal to mild lymphocytic infiltration or no significant lesions were commonly observed.

In ducks, similar but milder lesions than in the infected chickens were frequently observed in the upper respiratory tracts. At 4 days p.i., two of five ducks displayed rare mucoheterophilic infiltrate in the tracheas with mild edema in the submucosa (Fig. 2e). On 4 and 7 days p.i., in some ducks, microscopic lesions were observed in the lungs with mild congestion and mild mononuclear cell infiltration (Fig. 2f). Remaining organs of the infected ducks lacked significant microscopic lesions, including the gastrointestinal tracts, which are considered the main sites of LPAIVs replication in ducks. In addition, no lesions attributed to H9N2 infection were observed in the chickens and ducks of control group.

\section{Cytokines in trachea and ileum}

Because the differences in clinical signs and viral shedding patterns between chickens and ducks were observed in the current study, immune-related gene expression levels in the trachea and ileum were analyzed. As shown in Fig. 3, the differences in the IFN- $\alpha$ (IFNA) expression levels were not statistically significant between the two species. However, on 1 day p.i. and 4 days p.i., the IFN- $\beta$ (IFNB) expression and IFN- $\gamma$ (IFNG) expression in the ileum of chickens was significantly higher than in the ileum of ducks. Although IFN- $\gamma$ (IFNG) expressions levels were upregulated in the trachea of both species, the infection process resulted in higher levels of IFNG expression in the trachea of ducks.

Minimal changes in the levels of IL1B and IL6 were observed in ducks. However, the expression levels of IL1B and IL6 in trachea and ileum were significantly elevated in chickens compared to ducks on 1 day p.i. and 4 days p.i., although with varying levels. The infection process appeared to result in upregulation of IL2 in tissues of both ducks and chickens. Taken together, after infection with H9N2, ducks showed a milder IL1B and IL6 expressions, which was different from stronger IL1B and IL6 expressions observed in chickens.

\section{Serum HI antibodies}

The results for serum HI antibodies are shown in Fig. 4. Serum collected before 7 days p.i. remained negative against 
Table 2. Severity of histopathological lesions in chickens and ducks infected with $\mathrm{H} 9 \mathrm{~N} 2$

\begin{tabular}{lcccccc}
\hline & \multicolumn{2}{c}{ Day 4 p.i. } & & \multicolumn{2}{c}{ Day 7 p.i. } \\
\cline { 2 - 3 } \cline { 6 - 7 } & Chickens & Ducks & & Chickens & Ducks \\
\hline Tracheas & $++^{\mathrm{a}}$ & + & & + & $+/-$ \\
Lungs & + & + & & + & $+/-$ \\
Hearts & $+/-$ & - & & $+/-$ & - \\
Spleens & - & - & & - & - \\
Livers & $+/-$ & - & & - & - \\
Pancreata & ++ & - & & + & - \\
Kidneys & $+/-$ & - & & + & $+/-$ \\
Ilea & + & - & & + & - \\
Bursae of Fabricius & $+/-$ & - & & $+/-$ & - \\
\hline
\end{tabular}

aThe severity of lesions: $(-)$ none; $(+/-)$ minimal; $(+)$ mild; $(++)$ moderate; $(+++)$ high.

H9N2. From 10 days p.i. to the end of the experiment, chickens developed higher serum HI antibody titers than ducks. Moreover, serum HI antibodies seemed to have a longer persistence in chickens.

\section{Discussion}

In the current study, we experimentally inoculated ducks and chickens with a duck-origin H9N2. As a result, ducks exhibited minimal clinical signs, whereas chickens showed stronger response to the infection. Meanwhile, based on the results of viral shedding, chickens were infected and shed virus, although with shorter duration, indicating that this duck-origin $\mathrm{H} 9 \mathrm{~N} 2$ could be transmissible and cause clinical signs in chickens without prior adaption. In addition to the results of viral shedding, differential immune responses to H9N2 infection in the trachea and ileum of chickens and ducks were observed, suggesting ducks and chickens use different strategies in response to H9N2 infection in tissues where LPAIVs replicate.

In the field, H9N2 is an invasive agent and caused 5-30\% mortality with apparent clinical signs in the infected chickens characterized by decreased egg production, depression, edema of head, cyanosis of comb and legs (Lee et al., 2000). Meanwhile, it has been reported that the outcome of H9N2 could be exacerbated in chickens co-infected with other infectious agents (Bano et al., 2003). Therefore, these underlying conditions may provide an explanation for the higher mortality rates among chickens in the field in comparison with no mortality reported in our study. It is noteworthy that experiments should be conducted to evaluate the effect of these factors on ducks. With respect to viral shedding, chickens seemed to have higher viral titers and a longer duration of viral shedding in the trachea, while ducks had
Trachea 1 day p.i.

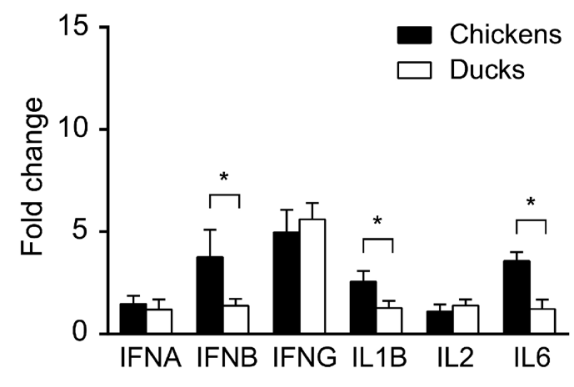

lleum 1 day p.i.

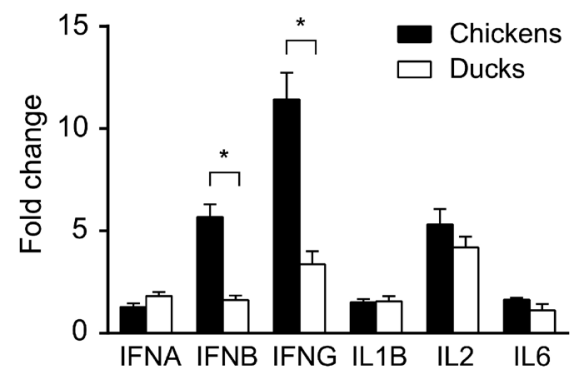

Trachea 4 days p.i.

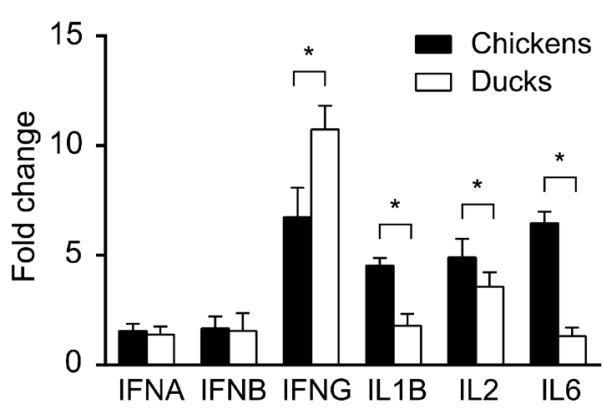

Ileum 4 days p.i.

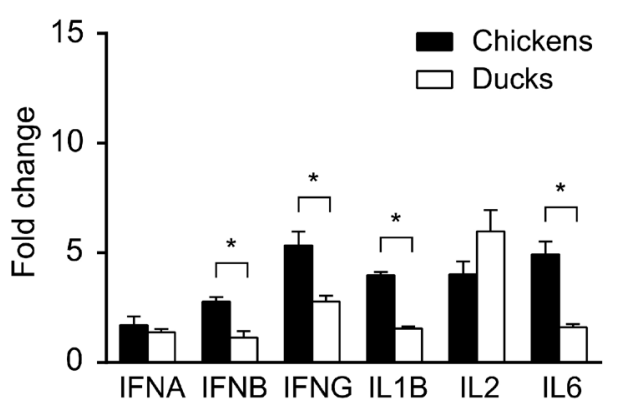

Fig. 3

Cytokine levels in the trachea and ileum of chickens and ducks infected with H9N2

Cytokine mRNAs were assayed by real-time RT-PCR and normalized to GAPDH. Data represent means \pm SE $(n=5)$. Asterisk indicates a significant difference. 
an extended period of viral shedding and higher viral titers found in CL swabs. Meanwhile, the positive recovery rate from CL swabs collected from ducks was relatively higher than from OP swabs, indicating that this duck-origin H9N2 replicated in respiratory tracts of ducks less efficiently than in their digestive tracts. Although the distribution of AIV receptors in these two species may contribute to the different viral shedding patterns (Gambarian et al., 2002), different immune responses to H9N2 infection between ducks and chickens also play a critical role.

While multiple cytokines and chemokines are produced by various kinds of host cells combating influenza infection, IFNs are principal cytokines involved in the antiviral response. In our study, ducks displayed lower overall IFNs expression in response to H9N2 infection in the ileum than chickens, which may provide an explanation for higher positive recovery rate in CL swabs and longer viral shedding observed in ducks, and a relatively shorter duration of viral shedding in chickens. However, ducks mounted a stronger IFNG expression in the trachea, which may help explain a quicker clearance of H9N2 in trachea and milder respiratory signs. Meanwhile, different IFNB expression levels were observed between ducks and chickens. Recent studies have shown that the chicken melanoma differentiationassociated protein 5 (chMDA5) strongly activated chicken IFNB promoter in response to AIV infection (Liniger et al., 2012), while retinoic acid-inducible gene I (RIG-I) present in ducks, which is apparently absent in chickens, played an essential role in the IFNB production triggered by AIV. Additionally, RIG-I was highly upregulated in ducks infected with HPAIVs, and slightly upregulated in ducks infected with LPAIVs (Barber et al., 2010). Studies have also demonstrated that the NS1 protein of AIV could inhibit IFNB signaling due to its interaction with MDA5 signaling pathway and RIG-I signaling pathway (Guo et al., 2007; Liniger et al., 2012). According to these reports, different susceptibility of the two species to the suppressive effect of the H9N2 NS1 gene on the IFNB expression may account for different levels of IFNB expression in ducks and chickens, which shared similarities to the results described by Adams et al. (2009) despite the fact that our study selected different tissues, different experimental approaches, time points, and LPAIV subtypes. In addition, a recent study revealed that Muscovy ducks (Cairina moschata) mounted overall stronger innate immune response to H9N2 infection than chickens (Huang et al., 2012). Several studies have demonstrated that expression of immune-related genes varied with different types of ducks, different origins of AIV isolates and different tissues (Cagle et al., 2012; Cornelissen et al., 2012; Maughan et al., 2013). Furthermore, age-related differences in immune responses to AIV infection have also reported in chickens and ducks (Reemers et al., 2010; Pantin-Jackwood et al., 2012). We, therefore, hypothesized that immune responses

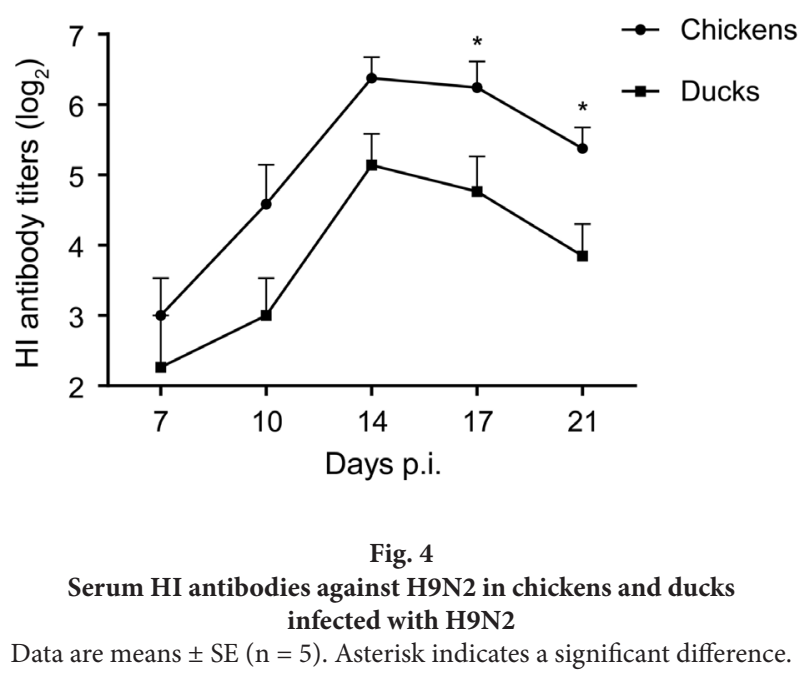

and pathogenesis in chickens and ducks in response to H9N2 infection may be affected by these factors. However, further studies are needed to fully elucidate the differences. Additionally, we also examined the expression levels of IL1B, IL2 and IL6. Our results showed that IL1B and IL6 were significantly upregulated in the trachea and ileum of chickens, which is different from their expression levels in samples collected from ducks. Recent studies have shown a positive correlation between the severity of the clinical manifestations and IL6 expression levels in animals (Marais et al., 2011; Chiaretti et al., 2013). It was possible to account for different manifestation of clinical signs in the two species after infection with H9N2. Interestingly, IL6 levels have been reported to play an important role in the development of mucosal IgA antibodies, which represent the first line of defense against exotic pathogens (Ramsay et al., 1994). In our study, infected chickens showed overall higher IL6 expression levels in the trachea and ileum, while IL6 levels in infected ducks were minimally changed. This led us to speculate that chickens may develop more mucosal IgA antibodies against H9N2 after infection than ducks, which might explain the frequent re-infections with LPAIV in the free ranging ducks in the field. As is known, IL2 is produced by Th1 cells, which leads to cellular immune response. After the infection, IL2 expression levels in both ducks and chickens were increased, emphasizing the role of IL2 in the cellular immune response to H9N2 infection.

In our study, chickens developed higher $\mathrm{HI}$ antibody titers than ducks. It was consistent with previous studies reporting that ducks typically generated poor antibody responses to influenza compared with mammals or even chickens, and further studies showed immunoglobulin genetics contributed to poor antibody responses to influenza infection or vaccination. Evidence also suggested that lack of secondary 
immune responses appeared to be a general feature of duck antibody responses (Kida et al., 1980; Lundqvist et al., 2006). Several inactivated influenza vaccines are currently used for controlling avian influenza in the laboratory and field studies (Tian et al., 2005; Nomura et al., 2012;). In one of these studies, vaccination of ducks with inactivated influenza vaccine induced lower antibody titers and required larger dosage in comparison with vaccination of chickens. A second boost, however, seemed to help the relatively high antibody titers to last, although the boost generated only slightly higher antibody titers (Tian et al., 2005). As our results and previous studies show, ducks may be more likely to be re-infected with $\mathrm{H} 9 \mathrm{~N} 2$ even at shorter intervals. We, therefore, suggest that the vaccination procedures for ducks should be carefully planned.

In many areas of China, free-range ducks are often in close contact with poultry, livestock, and humans in the same village or farm. AIVs-infected ducks have the opportunity to transmit the virus to chickens and other domesticated animals. Therefore, effective vaccination of ducks may be of good strategy for prevention and control of H9N2 transmission. Additionally, given the different outcomes of the H9N2 virus infection in ducks and chickens, different measures should be taken in vaccination and treatment of these animals.

Acknowledgements. This work was supported by the grant No. CARS-43-10 from the China Agriculture Research System.

\section{References}

Adams SC, Xing Z, Li J, Cardona CJ (2009): Immune-related gene expression in response to H11N9 low pathogenic avian influenza virus infection in chicken and Pekin duck peripheral blood mononuclear cells. Mol. Immunol. 46, 1744-1749. http://dx.doi.org/10.1016/j. molimm.2009.01.025

Alexander DJ (2000): A review of avian influenza in different bird species. Vet. Microbiol. 74, 3-13. http://dx.doi. org/10.1016/S0378-1135(00)00160-7

Bano S, Naeem K, Malik SA (2003): Evaluation of pathogenic potential of avian influenza virus serotype $\mathrm{H} 9 \mathrm{~N} 2$ in chickens. Avian Dis. 47, 817-822. http://dx.doi.org/10.1637/00052086-47.s3.817

Barber MRW, Aldridge JR, Webster RG, Magor KE (2010): Association of RIG-I with innate immunity of ducks to influenza. Proc. Natl. Acad. Sci. USA 107, 5913-5918 http://dx.doi. org/10.1073/pnas.1001755107

Bi J, Deng G, Dong J, Kong F, Li X, Xu Q, Zhang M, Zhao L, Qiao J (2010): Phylogenetic and Molecular Characterization of H9N2 Influenza Isolates from Chickens in Northern China from 2007-2009. PLoS One 5, e13063. http:// dx.doi.org/10.1371/journal.pone.0013063
Cagle C, Wasilenko J, Adams SC, Cardona CJ, To TL, Nguyen T, Spackman E, Suarez DL, Smith D, Shepherd E, Roth J, Pantin-Jackwood MJ (2012): Differences in pathogenicity, response to vaccination, and innate immune responses in different types of ducks infected with a virulent $\mathrm{H} 5 \mathrm{~N} 1$ highly pathogenic avian influenza virus from Vietnam. Avian Dis. 56, 479-487. http://dx.doi.org/10.1637/10030120511-Reg. 1

Chiaretti A, Pulitanò S, Barone G, Ferrara P, Romano V, Capozzi D, Riccardi R (2013): IL-1 $\beta$ and IL-6 Upregulation in Children with H1N1 Influenza Virus Infection. Mediat. Inflamm. 2013, 1-8. http://dx.doi.org/10.1155/2013/495848

Cornelissen JB, Post J, Peeters B, Vervelde L, Rebel JM (2012): Differential innate responses of chickens and ducks to lowpathogenic avian influenza. Avian Pathol. 41, 519-529. http://dx.doi.org/10.1080/03079457.2012.732691

Gambarian AS, Iamnikova SS, L'Vov D K, Robertson JS, Webster RG, Matrosovich MN (2002): Differences in receptor specificity between the influenza A viruses isolated from the duck, chicken, and human. Mol. Biol. (Mosk) 36, 542-549.

Gao R, Cao B, Hu Y, Feng Z, Wang D, Hu W, Chen J, Jie Z, Qiu H, Xu K, Xu X, Lu H, Zhu W, Gao Z, Xiang N, Shen Y, He Z, Gu Y, Zhang Z, Yang Y, Zhao X, Zhou L, Li X, Zou S, Zhang Y, Li X, Yang L, Guo J, Dong J, Li Q, Dong L, Zhu Y, Bai T, Wang S, Hao P, Yang W, Zhang Y, Han J, Yu H, Li D, Gao GF, Wu G, Wang Y, Yuan Z, Shu Y (2013): Human infection with a novel avian-origin influenza A (H7N9) virus. N. Engl. J. Med. 368, 1888-1897. http:// dx.doi.org/10.1056/NEJMoa1304459

Guan Y, Shortridge KF, Krauss S, Webster RG (1999): Molecular characterization of $\mathrm{H} 9 \mathrm{~N} 2$ influenza viruses: were they the donors of the "internal" genes of H5N1 viruses in Hong Kong? Proc. Natl. Acad. Sci. USA 96, 9363-9367. http:// dx.doi.org/10.1073/pnas.96.16.9363

Guo Z, Chen LM, Zeng H, Gomez JA, Plowden J, Fujita T, Katz JM, Donis RO, Sambhara S (2007): NS1 Protein of Influenza A Virus Inhibits the Function of Intracytoplasmic Pathogen Sensor, RIG-I. Am. J. Respir. Cell Mol. Biol. 36, 263-269. http://dx.doi.org/10.1165/rcmb.2006-0283RC

Huang Z, Fang D, Lv P, Bian X, Ruan X, Yan Y, Zhou J (2012): Differential cellular immune responses between chickens and ducks to H9N2 avian influenza virus infection. Vet. Immunol. Immunopathol. 150, 169-180. http://dx.doi. org/10.1016/j.vetimm.2012.09.010

Jackwood MW, Suarez DL, Hilt D, Pantin-Jackwood MJ, Spackman E, Woolcock P, Cardona C (2010): Biologic characterization of chicken-derived H6N2 low pathogenic avian influenza viruses in chickens and ducks. Avian Dis. 54, 120-125. http://dx.doi.org/10.1637/8987-070909 -ResNote. 1

Kida H, Yanagawa R, Matsuoka Y (1980): Duck influenza lacking evidence of disease signs and immune response. Infect. Immun. 30, 547-553.

Kishida N, Sakoda Y, Eto M, Sunaga Y, Kida H (2004): Co-infection of Staphylococcus aureus or Haemophilus paragallinarum exacerbates H9N2 influenza A virus infection in chickens. 
Arch. Virol. 149, 2095-2104. http://dx.doi.org/10.1007/ s00705-004-0372-1

Kwon JS, Lee HJ, Lee DH, Lee YJ, Mo IP, Nahm SS, Kim MJ, Lee JB, Park SY, Choi IS, Song CS (2008): Immune responses and pathogenesis in immunocompromised chickens in response to infection with the H9N2 low pathogenic avian influenza virus. Virus Res. 133, 187-194. http://dx.doi. org/10.1016/j.virusres.2007.12.019

Lee CW, Lee YJ, Swayne D, Senne D, Linares DJ, Suarez D (2007): Assessing potential pathogenicity of avian influenza virus: current and experimental system. Avian Dis. 51, 260-263. http://dx.doi.org/10.1637/7572-033106R.1

Lee CW, Song CS, Lee YJ, Mo IP, Garcia M, Suarez DL, Kim SJ (2000): Sequence analysis of the hemagglutinin gene of H9N2 Korean avian influenza viruses and assessment of the pathogenic potential of isolate MS96. Avian Dis. 44, 527-535. http://dx.doi.org/10.2307/1593091

Liniger M, Summerfield A, Zimmer G, McCullough KC, Ruggli N (2012): Chicken cells sense influenza A virus infection through MDA5 and CARDIF signaling involving LGP2. J. Virol. 86, 705-717. http://dx.doi.org/10.1128/ JVI.00742-11

Livak KJ, Schmittgen TD (2001): Analysis of relative gene expression data using real-time quantitative PCR and the 2(Delta Delta C(T)) Method. Methods 25, 402-408. http:// dx.doi.org/10.1006/meth.2001.1262

Lundqvist ML, Middleton DL, Radford C, Warr GW, Magor KE (2006): Immunoglobulins of the non-galliform birds: antibody expression and repertoire in the duck. Dev. Comp. Immunol. 30, 93-100. http://dx.doi.org/10.1016/j. dci.2005.06.019

Marais M, Maloney SK, Gray DA (2011): Brain IL-6- and PGdependent actions of IL-1 $\beta$ and lipopolysaccharide in avian fever. Am. J. Physiol. Regul. Integr. Comp. Physiol. 301, R791-R800. http://dx.doi.org/10.1152/ ajpregu.00136.2011

Matrosovich MN, Krauss S, Webster RG (2001): H9N2 influenza A viruses from poultry in Asia have human virus-like receptor specificity. Virology 281, 156-162. http://dx.doi. org/10.1006/viro.2000.0799

Maughan MN, Dougherty LS, Preskenis LA, Ladman BS, Gelb J, Spackman EV, Keeler CL, (2013): Transcriptional analysis of the innate immune response of ducks to different species-of-origin low pathogenic $\mathrm{H} 7$ avian influenza viruses. Virol. J. 10, 94. http://dx.doi.org/10.1186/1743$\underline{422 X-10-94}$

Munster VJ, Baas C, Lexmond P, Waldenstrom J, Wallensten A, Fransson T, Rimmelzwaan GF, Beyer WE, Schutten M, Olsen B, Osterhaus AD, Fouchier RA (2007): Spatial, temporal, and species variation in prevalence of influenza A viruses in wild migratory birds. PLoS Pathog. 3, e61. http://dx.doi.org/10.1371/journal.ppat.0030061

Nomura N, Sakoda Y, Soda K, Okamatsu M, Kida H (2012): An H9N2 influenza virus vaccine prepared from a non-path- ogenic isolate from a migratory duck confers protective immunity in mice against challenge with an $\mathrm{H} 9 \mathrm{~N} 2$ virus isolated from a girl in Hong Kong. J. Vet. Med. Sci. 74, 441-447. http://dx.doi.org/10.1292/jvms.11-0471

Olsen B, Munster VJ, Wallensten A, Waldenström J, Osterhaus ADME, Fouchier RAM (2006): Global Patterns of Influenza A Virus in Wild Birds. Science 312, 384-388. http:// dx.doi.org/10.1126/science. 1122438

Pantin-Jackwood MJ, Smith DM, Wasilenko JL, Cagle C, Shepherd E, Sarmento L, Kapczynski DR, Afonso CL (2012): Effect of age on the pathogenesis and innate immune responses in Pekin ducks infected with different H5N1 highly pathogenic avian influenza viruses. Virus Res. 167, 196-206. http://dx.doi.org/10.1016/j.virusres.2012.04.015

Peiris M, Yuen KY, Leung CW, Chan KH, Ip PL, Lai RW, Orr WK, Shortridge KF (1999): Human infection with influenza H9N2. Lancet 354, 916-917. http://dx.doi.org/10.1016/ S0140-6736(99)03311-5

Ramsay AJ, Husband AJ, Ramshaw IA, Bao S, Matthaei KI, Koehler G, Kopf M (1994): The role of interleukin-6 in mucosal IgA antibody responses in vivo. Science 264, 561-563. http://dx.doi.org/10.1126/science.8160012

Reed LJ, Muench H (1938): A simple method of estimating fifty percent endpoints. Am. J. Hyg. 27, 493-497.

Reemers SS, van Leenen D, Koerkamp MJ, van Haarlem D, van de Haar P, van Eden W, Vervelde, L (2010a): Early host responses to avian influenza $\mathrm{A}$ virus are prolonged and enhanced at transcriptional level depending on maturation of the immune system. Mol. Immunol. 47, 1675-1685. http://dx.doi.org/10.1016/j.molimm.2010.03.008

Spackman E, Gelb J, Preskenis LA, Ladman BS, Pope CR, PantinJackwood MJ, McKinley ET (2010): The pathogenesis of low pathogenicity $\mathrm{H} 7$ avian influenza viruses in chickens, ducks and turkeys. Virol. J. 7, 331. http://dx.doi. org/10.1186/1743-422X-7-331

Tian G, Zhang S, Li Y, Bu Z, Liu P, Zhou J, Li C, Shi J, Yu K, Chen $H$ (2005): Protective efficacy in chickens, geese and ducks of an H5N1-inactivated vaccine developed by reverse genetics. Virology 341, 153-162. http://dx.doi. org/10.1016/j.virol.2005.07.011

Webster RG, Bean WJ, Gorman OT, Chambers TM, Kawaoka Y (1992): Evolution and ecology of influenza A viruses. Microbiol. Rev. 56, 152-179.

$\mathrm{Xu}$ C, Fan W, Wei R, Zhao H (2004): Isolation and identification of swine influenza recombinant A/Swine/ Shandong/1/2003(H9N2) virus. Microbes Infect. 6, 919925. http://dx.doi.org/10.1016/j.micinf.2004.04.015

Zhang K, Zhang Z, Yu Z, Li L, Cheng K, Wang T, Huang G, Yang S, Zhao Y, Feng N, Fu J, Qin C, Gao Y, Xia X (2013): Domestic cats and dogs are susceptible to H9N2 avian influenza virus. Virus Res. 175, 52-57. http://dx.doi. org/10.1016/j.virusres.2013.04.004 